\title{
Relationship Between Shift Intensity and Insomnia Among Hospital Nurses in Korea: A Cross-sectional Study
}

\author{
Yuhjin Chung ${ }^{1}$, Hyunjoo Kim ${ }^{2}$, Dong-Hee Koh ${ }^{3}$, Ju-Hyun Park', Seohyun Yoon ${ }^{5}$ \\ ${ }^{1}$ Department of Preventive Medicine, Graduate School of Public Health, Seoul National University, Seoul, Korea; ${ }^{2}$ Department of Occupational and \\ Environmental Medicine, Ewha Womans University Mokdong Hospital, Seoul, Korea; ${ }^{3}$ Department of Occupational and Environmental Medicine, \\ International St. Mary's Hospital, Incheon, Korea; ${ }^{4}$ Department of Statistics, Dongguk University, Seoul, Korea; ${ }^{5}$ wha Medical Research Institute, \\ Ewha Womans University School of Medicine, Seoul, Korea
}

Objectives: This study explored the relationship between shift intensity and insomnia among hospital nurses.

Methods: The participants were 386 female hospital nurses who underwent a special health examination for night workers in 2015. The Korean Insomnia Severity Index (ISI), indices of shift work intensity, and other covariates such as amount of exercise, level of alcohol consumption, employment duration, and hours worked were extracted from the health examination data. The indices for shift intensity were (1) number of 3 consecutive night shifts and (2) number of short recovery periods after a previous shift, both assessed over the prior 3 months. Multiple logistic regression analysis adjusted for the aforementioned covariates was performed to evaluate the association of shift intensity with insomnia, defined as an ISI score of $\geq 8$.

Results: The nurses with insomnia tended to be younger $(p=0.029)$, to have worked 3 consecutive night shifts more frequently $(p<0.001)$, to have experienced a greater number of short recovery periods after the previous shift $(p=0.021)$, and to have worked for more hours $(p=0.006)$ than the nurses without insomnia. Among the other variables, no statistically significant differences between groups were observed. Experiences of 3 or more consecutive night shifts (odds ratio [OR], 2.33; 95\% confidence interval [Cl], 1.29 to 4.20 ) and 3 or more short recovery periods $(\mathrm{OR}, 2.01 ; 95 \% \mathrm{Cl}, 1.08$ to 3.73$)$ were associated with increased odds of insomnia.

Conclusions: The results suggest that decreasing the shift intensity may reduce insomnia among hospital nurses working rotating shifts.

Key words: Nurses, Shift work, Night work, Insomnia, Shift intensity

\section{INTRODUCTION}

Nursing is a well-known example of an occupation that requires shift work, which is known to be associated with physi-

Received: November 12, 2020 Accepted: November 26, 2020

Corresponding author: Seohyun Yoon

Ewha Medical Research Institute, Ewha Womans University School of Medicine, 1071 Anyangcheon-ro, Yangcheon-gu, Seoul 07985, Korea E-mail: shyoon727@gmail.com

This is an Open Access article distributed under the terms of the Creative Commons Attribution Non-Commercial License (https://creativecommons.org/licenses/bync/4.0/) which permits unrestricted non-commercial use, distribution, and reproduction in any medium, provided the original work is properly cited. cal health problems such as metabolic syndrome [1] and heart disease [2], as well as mental health problems such as depression, anxiety, and insomnia [3-5]. In particular, insomnia among nurses has been reported to lead to work-related mistakes, potentially threatening patient safety $[6,7]$.

Associations between shift work and insomnia $[8,9]$, decreased sleep quality [10], daytime sleepiness [3], and fatigue [11] among rotating shift nurses have been consistently reported. To combat such problems, previous studies have suggested individual-level strategies in which a nurse's lifestyle habits and personality characteristics are analyzed to devise a solution $[12,13]$. However, as individual-level interventions have shown limited 
effectiveness, more effective organization-level interventions, such as improvements in shift work schedules, provision of nap breaks, increased social support, and improvements in the work environment, may be necessary $[14,15]$.

The strategic rearrangement of shift schedules is a potential interventional measure, but its effectiveness has not been adequately confirmed by empirical epidemiological studies. Most studies dealing with the health effects of rotating shifts among nurses have compared shift workers and daytime regular workers; only a few quantitative studies have compared 2-shift and 3 -shift work $[16,17]$. According to a recent review article, engagement in shift work has been the sole independent variable in most Korean studies on this topic; the relationships between more specific characteristics of shift work (e.g., shift work type, duration, and frequency) and health problems have been explored in only a few studies [18]. In a cross-sectional study, Chaiard et al. [19] reported that work schedules including more than 10 night shifts per month were associated with difficulty initiating sleep among nurses; however, the impacts of various components of shift work on nurses' sleep have not been fully elucidated.

Härmä et al. [20] aimed to evaluate health problems among nurses by examining 4 work patterns using data from the electronic work hour databases of various hospitals. They suggested measurement indices for the time of day of the work, hours worked, shift intensity, and social aspects of working hours. In reference to this study, Yoon et al. [21] proposed specific work hour indices. In particular, based on 2 indices of shift-work intensity (the number of 3 consecutive night shifts and the number of short recovery periods) they proposed an evaluation method to better reflect the situation in Korea.

Shin and Kim [22] reported that working 3 consecutive night shifts was associated with insomnia among hospital nurses. In that study, few Korean studies have been conducted on the relationship between the intensity of shift work and symptoms of insomnia; however, in one example, they used actigraphy to evaluate changes in sleep indices over 6 days according to the time of the day during which the nurse worked. Thus, that study had a limited capacity to explain the relationship between shift work schedules and clinically significant insomnia symptoms.

The purpose of the current study was to investigate the association between the intensity of shift work and reports of insomnia symptoms among nurses working at a university hospital to provide a foundation for establishing policies on work schedule design for health of nurses.

\section{METHODS}

\section{Study Participants}

The participants of this study were female nurses working rotating shifts at a university hospital. These nurses underwent a special medical examination for night shift workers, as well as a general medical examination, in 2015. In Korea, the Occupational Safety and Health Act requires employers to provide general medical examinations to all workers and special medical examinations to those who work under hazardous conditions. A special medical examination for night shift workers has been implemented to combat health problems such as sleep disorders, cerebrovascular and cardiovascular disease, and breast cancer among these workers. This study included nurses who had worked at least 1 night shift within the 3 months prior to the special medical examination, and a total of 386 participants were included in the analysis.

\section{Main Variables \\ Independent variables}

To assess shift work intensity, the aforementioned indices developed by Yoon et al. [21] were used. Values were calculated using data on individual work schedules, collected for the evaluation of exposure to harmful factors as part of the preliminary investigation in the special medical examinations for night shift workers. Computerized personal work schedule data, where the individual type of work is assessed daily, coded (as night, daytime, evening, or off duty) were used to investigate each individual's work schedule for the 3 months prior to the medical examination. A short recovery period was defined by Yoon et al. [21] as including night-off-day, night-off-evening, and evening-off-day work schedules.

In the present study, the number of 3 consecutive night shifts and the number of short recovery periods over the past 3 months were used as 2 separate variables of shift work intensity. Both variables had potential values of 0,1 to 2 , and 3 or more. The Supplemental Material 1 shows the distributions of both observations of variables.

\section{Dependent variables}

Data on insomnia symptoms were extracted from the database used for the special medical examination for night shift workers. The medical examination data were used to assess the symptoms of insomnia based on the Korean Insomnia Severity Index (ISI), which is a version (translated by Cho et al. 
[23]) of the original index developed by Bastien et al. [24]. The ISI includes a total of 7 questions, and the total score is calculated by summing the scores of the questions ( $0-4$ points for each). A higher score indicates a greater severity of insomnia symptoms. Since an ISI score of 8 is used to indicate minor insomnia, insomnia symptoms were considered to be present for an ISI score of 8 or greater and absent for a score of less than 8. The Supplemental Material 2 shows the distribution of ISI score.

\section{Confounding variables}

Confounding variables included age, employment duration, number of hours worked, work department, amount of exercise, and level of alcohol consumption. Age and employment duration data were extracted from a special medical examination database; total time worked over the past 3 months and work department data were obtained from the aforementioned computerized work schedule database; and information on lifestyle habits, such as exercise and alcohol consumption, were extracted from a general medical examination database. Work hours were measured as the prescribed work hours, according to the employment rules or labor contracts within the legal standard of work hours. Among the study participants, the prescribed work hours were 8 hours for morning and afternoon shifts, 9.5 hours for night shifts, and 30 minutes of hand-off time per shift. However, we were unable to collect information on the pre-work time associated with the preparation of goods, medicines, and treatment tools or time spent processing delayed work during work hours.

The work department was defined as either a special sector (the operating room, recovery room, emergency room, and intensive care unit) or the general ward. The information on lifestyle habits extracted from the general medical examination database was classified according to the 2018 counseling manual of National Health Screening Program provided by the Korean Centers for Disease Control and Prevention [25].

With regard to alcohol consumption, participants were classified as non-drinkers, light drinkers, moderate drinkers, or heavy drinkers. The evaluation of alcohol consumption was based on the report [25], which referred to the guidelines [26] of the National Institute on Alcohol Abuse and Alcoholism in the United States. The report was refered by the Korean guidelines established by Lee et al. [27] in 2019.

Among female younger than 65 years, light drinkers were defined as those who did not consume more than 4 drinks per week or 2 drinks on 1 occasion. Those who consumed more than 5 drinks on 1 occasion or 7 drinks per week were considered heavy drinkers. Moderate drinkers were those whose consumption habits fell between those of light and heavy drinkers.

The amount of exercise was categorized as low, moderate, or high. The classification criteria were as follows: low exercise, less than 150 minutes ( 2 hours and 30 minutes) of aerobic activity per week; high exercise, more than 300 minutes ( 5 hours) of medium-intensity aerobic activity performed 3-5 times per week; and moderate exercise, an amount between low and high exercise. This classification was based on the 2008 Physical Activity Guidelines for Americans [28], which are also reflected in the guidelines of Kim et al. [29].

\section{Statistical Analysis}

Stata SE version 16.1 (StataCorp., College Station, TX, USA) was used for statistical analysis. The distribution of each variable was presented for each group of participants: that is, the group with insomnia and the group without insomnia. The independent $t$-test was performed for continuous variables, including age, employment duration, and total time worked over the prior 3 months, to evaluate the differences between the 2 groups. For work department, the number of 3 consecutive night shifts, and the number of short recovery periods, the chi-square test was conducted with each of the latter 2 parameters classified as 0,1 or 2 , or 3 or more times.

To clarify the relationship between the intensity of shift work and insomnia symptoms, odds ratios (ORs) were calculated using univariate analysis, and multiple logistic regression analysis adjusted for confounding variables was performed. The confounding variables included were age, alcohol consumption, amount of exercise, employment duration, work department, and total time worked over the past 3 months. Furthermore, an interaction analysis was performed to determine whether statistically significant interactions between independent variables were present.

\section{Ethics Statement}

This study was approved by the Institutional Review Board of Ewha Womans University Mokdong Hospital (EUMC 201805-017). 


\section{RESULTS}

\section{Characteristics of Study Participants and Symptoms of Insomnia}

On average, the nurses in the group with insomnia symptoms were statistically significantly younger than those in the group without symptoms ( $31.9 \pm 5.6$ vs. $33.2 \pm 6.2$ years, respectively; $p=0.029$ ). The number of total time worked over the past 3 months was statistically significantly higher among the group with insomnia symptoms than among the group without symptoms (458.6 \pm 30.1 vs. $446.7 \pm 49.1$ hours, respectively; $p=0.006)$. Seventy nurses $(32.6 \%)$ in the group without insomnia symptoms and 33 (19.3\%) in the group with insomnia symptoms had not worked 3 consecutive night shifts; 96 nurses (44.7\%) in the former group and 70 (40.9\%) in the latter group had done so $1-2$ times; and 49 nurses (22.8\%) in the former group and 68 (39.8\%) in the latter group had done so at least 3 times, indicating that the presence of insomnia symptoms tended to be associated with a greater number of these shifts $(p<0.001)$. Regarding short recovery periods, 70 participants (32.6\%) in the group without insomnia symptoms and $36(21.1 \%)$ in the group with insomnia symptoms had experienced no such recovery periods in the past 3 months; 100 participants (46.5\%) in the former group and $84(49.1 \%)$ in the latter group had experienced $1-2$ instances; and 45 participants (20.9\%) in the former group and 51 (29.8\%) in the latter group had experienced 3 or more instances of short recovery periods, which suggests that the presence of insomnia symptoms tended to be associated with a greater number of short recovery periods $(p=0.021)$. The mean employment duration was not statistically significantly different between the groups and no significant intergroup difference was observed with regard to work department, alcohol consumption, or exercise (Table 1).

\section{Relationship Between Shift Intensity and Insomnia Symptoms}

In the univariate analysis (Table 2), the OR for insomnia symptoms for 3 consecutive night shifts over the past 3 months was 1.55 (95\% confidence interval [Cl], 0.92 to 2.59 ) for those who had experienced $1-2$ instances and $2.94(95 \% \mathrm{Cl}, 1.69$ to 5.12$)$ for those who had experienced 3 or more instances, relative to those who had not worked any such shifts. In the multiple logistic regression analysis adjusted for age, employment duration, total time worked over the past 3 months, alcohol con-
Table 1. Characteristics of the study population

\begin{tabular}{|c|c|c|c|}
\hline \multirow{3}{*}{ Characteristics } & \multicolumn{2}{|c|}{ Insomnia } & \multirow{3}{*}{$p$-value } \\
\hline & \multirow{2}{*}{$\frac{\text { No }(n=215)}{<8 \text { score }}$} & \multirow{2}{*}{$\frac{\text { Yes }(n=171)}{\geq 8 \text { score }}$} & \\
\hline & & & \\
\hline Age (y) & $\begin{array}{c}33.2 \pm 6.2 / \\
{[25,28]}\end{array}$ & $\begin{array}{c}31.9 \pm 5.6 / \\
{[26,51]}\end{array}$ & $0.029^{1}$ \\
\hline Duration of employment (y) & $\begin{array}{l}6.9 \pm 5.6 / \\
{[1,32]}\end{array}$ & $\begin{array}{c}6.0 \pm 5.8 / \\
{[1,29]}\end{array}$ & $0.140^{1}$ \\
\hline $\begin{array}{l}\text { Total time worked over the past } \\
3 \mathrm{mo}(\mathrm{hr}) \text { [min, max] }\end{array}$ & $\begin{array}{c}446.7 \pm 49.1 / \\
{[83,517]}\end{array}$ & $\begin{array}{c}458.6 \pm 30.1 / \\
{[337,511]}\end{array}$ & $0.006^{1}$ \\
\hline Department ${ }^{3}$ & & & $0.247^{2}$ \\
\hline General ward & $132(61.5)$ & $95(55.6)$ & \\
\hline Special sector ${ }^{4}$ & $83(38.6)$ & $76(44.4)$ & \\
\hline Alcohol consumption & & & $0.208^{2}$ \\
\hline None & $103(47.9)$ & 68 (39.8) & \\
\hline Light & $40(18.6)$ & $30(17.5)$ & \\
\hline Moderate & $46(21.4)$ & $41(24.0)$ & \\
\hline Heavy & $26(12.1)$ & $32(18.7)$ & \\
\hline Amount of exercise & & & $0.218^{2}$ \\
\hline High & $102(47.4)$ & $83(48.5)$ & \\
\hline Moderate & $64(29.8)$ & 39 (22.8) & \\
\hline Low & $49(22.8)$ & $49(28.7)$ & \\
\hline $\begin{array}{l}\text { No. of } 3 \text { consecutive night shifts } \\
\text { during the past } 3 \text { mo }\end{array}$ & & & $<0.001^{2}$ \\
\hline 0 & 70 (32.6) & 33 (19.3) & \\
\hline $1-2$ & $96(44.7)$ & $70(40.9)$ & \\
\hline$\geq 3$ & $49(22.8)$ & 68 (39.8) & \\
\hline $\begin{array}{l}\text { No. of short recovery periods afte } \\
\text { shift during the past } 3 \text { mo }\end{array}$ & the previous & & $0.021^{2}$ \\
\hline 0 & 70 (32.6) & $36(21.1)$ & \\
\hline $1-2$ & $100(46.5)$ & $84(49.1)$ & \\
\hline$\geq 3$ & $45(20.9)$ & $51(29.8)$ & \\
\hline
\end{tabular}

Values are presented as mean \pm standard deviation/[minimum, maximum] or number (\%).

1 Independent $t$-test; dependent $t$-test.

${ }^{2}$ Pearson chi-square test.

${ }^{3}$ Department of the hospital.

${ }^{4}$ Includes the operating room, intensive care unit, recovery room, and emergency department.

sumption, and exercise, the OR was $1.37(95 \% \mathrm{Cl}, 0.80$ to 2.35$)$ for those who had worked $1-2$ shifts and $2.33(95 \% \mathrm{Cl}, 1.29$ to 4.20) for those who had worked 3 or more shifts, compared to those who had not worked any such shifts.

Regarding short recovery periods, in the univariate analysis, the OR for insomnia symptoms was $1.63(95 \% \mathrm{Cl}, 0.99$ to 2.68$)$ for those who had experienced 1-2 short recovery periods over the past 3 months and $2.20(95 \% \mathrm{Cl}, 1.25$ to 3.89$)$ for those who had experienced 3 or more, relative to those with no short recovery periods. In the multiple logistic regression analysis ad- 
Table 2. Association of shift intensity with insomnia among hospital nurses in $2015(n=386)$

\begin{tabular}{|c|c|c|}
\hline Variables & Crude model & Adjusted model $^{1}$ \\
\hline Age & $0.96(0.93,1.00)$ & $0.94(0.86,1.02)$ \\
\hline Duration of employment & $0.97(0.94,1.01)$ & $1.05(0.97,1.15)$ \\
\hline Total time worked & $1.01(1.00,1.01)$ & $1.00(1.00,1.01)$ \\
\hline \multicolumn{3}{|l|}{ Department ${ }^{2}$} \\
\hline General ward & 1.00 (reference) & 1.00 (reference) \\
\hline Special sector ${ }^{3}$ & $1.27(0.85,1.91)$ & $1.41(0.89,2.22)$ \\
\hline \multicolumn{3}{|l|}{ Alcohol consumption } \\
\hline None & 1.00 (reference) & 1.00 (reference) \\
\hline Light & $1.14(0.65,2.00)$ & $1.14(0.62,2.09)$ \\
\hline Moderate & $1.35(0.80,2.27)$ & $1.10(0.63,1.93)$ \\
\hline Heavy & $1.86(1.02,3.40)$ & $1.48(0.78,2.83)$ \\
\hline \multicolumn{3}{|l|}{ Amount of exercise } \\
\hline High & 1.00 (reference) & 1.00 (reference) \\
\hline Moderate & $0.75(0.46,1.22)$ & $0.82(0.49,1.38)$ \\
\hline Low & $1.23(0.75,2.01)$ & $1.35(0.81,2.27)$ \\
\hline \multicolumn{3}{|c|}{$\begin{array}{l}\text { No. of } 3 \text { consecutive night shifts } \\
\text { during the past } 3 \text { mo }\end{array}$} \\
\hline 0 & 1.00 (reference) & 1.00 (reference) \\
\hline $1-2$ & $1.55(0.92,2.59)$ & $1.37(0.80,2.35)$ \\
\hline$\geq 3$ & $2.94(1.69,5.12)$ & $2.33(1.29,4.20)$ \\
\hline \multicolumn{3}{|c|}{$\begin{array}{l}\text { No. of short recovery periods after the } \\
\text { previous shift during the past } 3 \text { mo }\end{array}$} \\
\hline 0 & 1.00 (reference) & 1.00 (reference) \\
\hline $1-2$ & $1.63(0.99,2.68)$ & $1.45(0.85,2.47)$ \\
\hline$\geq 3$ & $2.20(1.25,3.89)$ & $2.01(1.08,3.73)$ \\
\hline
\end{tabular}

Values are presented as odds ratio ( $95 \%$ confidence interval).

${ }^{1}$ Adjusted for age, duration of employment, total time worked over the past 3 months, department, alcohol consumption, and exercise.

${ }^{2}$ Department of the hospital.

${ }^{3}$ Includes the operating room, intensive care unit, recovery room, and emergency department.

justed for the aforementioned confounding variables, the $\mathrm{OR}$ was $1.45(95 \% \mathrm{Cl}, 0.85$ to 2.47$)$ for nurses with $1-2$ short recovery periods and $2.01(95 \% \mathrm{Cl}, 1.08$ to 3.73$)$ for those with 3 or more, relative to those with no short recovery periods (Table 2).

In the analysis of the model with respect to interactions among the independent variables, no statistically significant interactions were observed.

\section{DISCUSSION}

The overall prevalence of insomnia symptoms in this study was $46.5 \%$. In previous studies, the prevalence of insomnia symptoms among nurses working rotating shifts has ranged from $34.3 \%$ to $55.0 \%$ [30-32]. As each study used a different classification system for insomnia symptoms, the differences in prevalence among the studies were notable [33]. Therefore, it is difficult to directly compare the prevalence rate found in the current study with those of previous studies.

In the current study, the intensity of shift work was an independent factor associated with an increased risk of insomnia symptoms among rotating shift nurses. In particular, we found that the risk increased approximately 2.3-fold if participants worked 3 consecutive night shifts more than once a month and more than 2.0-fold if a short recovery period was experienced more than once a month, after adjustment for major confounding variables. These findings align with those of a recent study. In 2018, Härmä et al. [34] conducted a follow-up study of 7727 nurses and reported that the ORs for fatigue and difficulty falling asleep were significantly greater among those who had experienced a higher frequency of short shift intervals and shifts on 3 consecutive nights.

In this study, we confirmed the association between the number of 3 consecutive night shifts as an index of the intensity of shift work, and an increased risk of insomnia symptoms. Ergonomics textbooks similarly recommend limiting consecutive night work to 2 days. In 1976, Knauth and Rutenfranz [35] conducted an experimental study on shift work and circadian rhythm. They reported that the circadian rhythm recovered within 2 days after the end of a night shift. Although experimental studies have yielded the suggestion that consecutive night shifts should be limited to 2 days, few studies have actually been conducted to investigate the relationship between shift work schedule and health problems in shift workers. Our study provides a more robust basis for the guidelines that nurses' work schedules should be designed to prevent shifts on 3 consecutive nights in order to protect their health.

Ensuring an adequate recovery period is important when aiming to design healthy work schedules for nurses. In the abovementioned 2018 study by Härmä et al. [34], a short recovery period was defined as an interval of less than 11 hours between shifts, and its association with various health indicators, including sleep-onset disorder, was reported. In 2013, Eldevik et al. [3] demonstrated that an increased risk of insomnia was associated with a higher frequency of "quick returns," defined as less than 11 hours off work between shifts, over a period of a year in a study of 5400 Norwegian nurses. Otherwise, however, the effect of short recovery periods on the health of nurses performing rotating shift work has been rarely researched. 
The International Labor Organization recommends that the interval between work shifts should be 11 hours or more [36]. Thus, an interval of less than 11 hours between shifts can be considered an extremely short recovery period. As our study included very few cases in which the interval between shifts was less than 11 hours, we used work schedule types to define a short recovery period, referring to insights from a worksite interview conducted by Choi [37] in 2018. An excerpt of that oral interview is given below:

On the last day of a 3-night shift, it feels like my body is literally breaking down... when the night shifts were reduced from 3 to 2, we felt better, it was good, but the night-off-evening and nightoff-off-day work schedules are still too much to handle.

Choi [37] conducted a mixed-methods study involving ward nurses. In that study, a short recovery period was described as inducing physical and mental impairment and the researchers found that increased work intensity exacerbated these risks in the context of routine excessive overtime. Similarly, we calculated an index of short recovery period that reflected realworld conditions and provided a basis for establishing concrete measures to reduce the health risk. This demonstrates that a study reflecting actual field experience can be useful to derive practical solutions for this problematic situation.

A relatively new approach is necessary to establish an evaluation method for shift work intensity. In the study by Härmä et al. [34], the measurement period for the intensity of shift work in relation to fatigue and sleep-onset disorder was 3 months. The variables for shift intensity used in our study were also calculated using data from the 3 months prior to each individual's medical examination. This method includes a sufficient exposure period to allow clinically meaningful insomnia symptoms to arise and it takes into account the characteristics of the actual work schedules of nurses. In general, the intensity of shift work may increase among nurses working in general hospitals in Korea when department members are restricted from working at night due to pregnancy or childbirth or when a workforce reduction occurs due to parental leave or resignation. Furthermore, it was assumed that vacant positions are typically filled within 3 months and that high-risk schedules, such as those involving 3 consecutive night shifts, are not assigned every month. Ropponen et al. [38] conducted a case-crossover study on the relationship between the intensity of shift work and sick leave taken by nurses. In that study, the intensity of shift work was assessed by calculating the number of shifts involving 2 or 4 consecutive nights within a 4-week period. Like- wise, the method of evaluation of shift work intensity may differ. Therefore, in the future, measurement methods should be explored in various contexts to confirm the association of shift work intensity with health problems.

The limitations of this study are as follows. First, it was crosssectional in nature. Thus, the presence of a causal relationship between the intensity of shift work and symptoms of insomnia could not be ascertained based on the study results alone. However, insomnia symptoms were reported on the day of the health examination, and the independent variables used were shift work intensity indices calculated for the 3-month period prior to the examination. In other words, given that the exposure temporally preceded the health outcome, a causal relationship certainly is possible. Second, various harmful factors and health status variables that can relate to insomnia symptoms were not examined. In previous studies, personal factors such as anxiety and depression [32], chronotype [39] were found to be associated with insomnia symptoms. If the effects of these factors are taken into consideration, the magnitude of the association between shift work intensity and insomnia observed in this study may be reduced. This limitation should be addressed in prospective follow-up research. Third, shift work intensity and hours worked were assessed using a computerized work schedule database. Since hours worked were defined as prescribed work hours, the numbers of actual work hours could have been greater. This is a non-discriminatory misclassification, and as the number of hours worked was a confounding variable, its effect on the association between shift-work intensity and insomnia symptoms is unlikely to have been meaningful. Fourth, the presence of insomnia symptoms was investigated through participants' self-reports. However, we used structured indices that had been verified in several prior studies and that the subjective quality of sleep perceived by an individual is also important in assessing sleep health.

The significance of this study is that shift work intensity was assessed through objective indicators and its association with insomnia symptoms was suggested, which is particularly noteworthy given that research on this topic is limited. To the best of our knowledge, this is the first Korean study to investigate the relationship between indicators of shift work intensity and health problems using objective data regarding the intensity of shift work.

In terms of government policy, our findings suggest the need to work to prohibit or at least reduce shifts on 3 consecu- 
tive nights, given that not only the frequency but also the distribution of night work is important in rotating shift work. In addition, shift workers should be provided with adequate sufficient recovery periods especially after night work and evening work. In qualitative studies, short recovery periods (described as night-off-evening, night-off-day, and evening-offday schedules) have been reported by nurses in the field to be a major burden, and such short periods were found to increase the risk of insomnia symptoms in our study.

Furthermore, as designing a reasonable work schedule for nurses without increasing the number of staff is practically impossible, the problem may not be overcome at the level of individual hospitals. In particular, in Korea, where the private sector accounts for $90 \%$ of the total healthcare system and public institutions play only a partial role, the recruitment of nursing personnel requires intervention at the national level. Reducing the intensity of shift work among nurses is not only necessary for the protection of their health, but also related to the health and safety of the public.

\section{SUPPLEMENTAL MATERIALS}

Supplemental materials are available at https://doi.org/10. 3961/jpmph.20.555.

\section{CONFLICT OF INTEREST}

The authors have no conflicts of interest associated with the material presented in this paper.

\section{FUNDING}

None.

\section{ACKNOWLEDGEMENTS}

None.

\section{AUTHOR CONTRIBUTIONS}

Conceptualization: YC. Data curation: JHP, SY. Formal analysis:YC. Methodology: JHP, DHK, HK. Funding acquisition: None. Writing - original draft: YC. Writing - review \& editing: YC, HK, SY, JHP, DHK.

\section{ORCID}

Yuhjin Chung https://orcid.org/0000-0001-9184-5612 Hyunjoo Kim https://orcid.org/0000-0003-0375-9939 Dong-Hee Koh https://orcid.org/0000-0002-2868-4411 Ju-Hyun Park https://orcid.org/0000-0001-9675-6475 Seohyun Yoon https://orcid.org/0000-0003-4355-2596

\section{REFERENCES}

1. Qiao H, Beibei Z, Chong T, Tieying Z, Yuzhi G, Jing M, et al. Both frequency and duration of rotating night shifts are associated with metabolic parameters: a cross-sectional study. Sleep Med 2020;71:89-96.

2. Kervezee L, Kosmadopoulos A, Boivin DB. Metabolic and cardiovascular consequences of shift work: the role of circadian disruption and sleep disturbances. Eur J Neurosci 2020;51(1): 396-412.

3. Eldevik MF, Flo E, Moen BE, Pallesen S, Bjorvatn B. Insomnia, excessive sleepiness, excessive fatigue, anxiety, depression and shift work disorder in nurses having less than 11 hours inbetween shifts. PLoS One 2013;8(8):e70882.

4. Hu Y, Niu Z, Dai L, Maguire R, Zong Z, Hu Y, et al. The relationship between sleep pattern and depression in Chinese shift workers: a mediating role of emotional exhaustion. Aust J Psychol 2020;72(1):68-81.

5. Shen SH, Yen M, Yang SL, Lee CY. Insomnia, anxiety, and heart rate variability among nurses working different shift systems in Taiwan. Nurs Health Sci 2016;18(2):223-229.

6. Gold DR, Rogacz S, Bock N, Tosteson TD, Baum TM, Speizer FE, et al. Rotating shift work, sleep, and accidents related to sleepiness in hospital nurses. Am J Public Health 1992;82(7):10111014.

7. Johnson AL, Jung L, Song Y, Brown KC, Weaver MT, Richards KC. Sleep deprivation and error in nurses who work the night shift. J Nurs Adm 2014;44(1):17-22.

8. Booker LA, Magee M, Rajaratnam SM, Sletten TL, Howard ME. Individual vulnerability to insomnia, excessive sleepiness and shift work disorder amongst healthcare shift workers. A systematic review. Sleep Med Rev 2018;41:220-233.

9. Flo E, Pallesen S, Magerøy N, Moen BE, Grønli J, Hilde Nordhus I, et al. Shift work disorder in nurses--assessment, prevalence and related health problems. PLoS One 2012;7(4):e33981.

10. Lin Y, Shan PY, Jiang WJ, Sheng C, Ma L. Subjective cognitive decline: preclinical manifestation of Alzheimer's disease. Neu- 
rol Sci 2019;40(1):41-49.

11. Min A, Min H, Hong HC. Work schedule characteristics and fatigue among rotating shift nurses in hospital setting: an integrative review. J Nurs Manag 2019;27(5):884-895.

12. Storemark SS, Fossum IN, Bjorvatn B, Moen BE, Flo E, Pallesen S. Personality factors predict sleep-related shift work tolerance in different shifts at 2-year follow-up: a prospective study. BMJ Open 2013;3(11):e003696.

13. Vedaa Ø, Krossbakken E, Grimsrud ID, Bjorvatn B, Sivertsen B, Magerøy $\mathrm{N}$, et al. Prospective study of predictors and consequences of insomnia: personality, lifestyle, mental health, and work-related stressors. Sleep Med 2016;20:51-58.

14. Lim S, Han K, Cho H, Baek H. Shift-work nurses' work environments and health-promoting behaviours in relation to sleep disturbance: a cross-sectional secondary data analysis. J Clin Nurs 2019;28(9-10):1538-1545.

15. Sun Q, Ji X, Zhou W, Liu J. Sleep problems in shift nurses: a brief review and recommendations at both individual and institutional levels. J Nurs Manag 2019;27(1):10-18.

16. Byeon YS. The effects of 2 or 3 shift rotation on the fatigue and sleep. J Korean Biol Nurs Sci 2005;7(2):5-15 (Korean).

17. Chae MJ, Choi SJ. Comparison of shift satisfaction, sleep, fatigue, quality of life, and patient safety incidents between two-shift and three-shift intensive care unit nurses. J Korean Crit Care Nurs 2020;13(2):1-11 (Korean).

18. Yoon S, Kang CW, Kee D, Kim H. Working time patterns and health among Korean nurses: a literature review. J Korean Soc Occup Environ Hyg 2018;28(4):331-345 (Korean).

19. Chaiard J, Deeluea J, Suksatit B, Songkham W, Inta N, Stone TE. Sleep disturbances and related factors among nurses. Nurs Health Sci 2019;21(4):470-478.

20. Härmä M, Ropponen A, Hakola T, Koskinen A, Vanttola P, Puttonen $S$, et al. Developing register-based measures for assessment of working time patterns for epidemiologic studies. Scand J Work Environ Health 2015;41(3):268-279.

21. Yoon S, Park JH, Kee D, Koh TK, Kang CW, Koh DH, et al. Assessment of working time pattern for hospital nurses. J Ergon Soc Korea 2018;37(6):759-769 (Korean).

22. Shin S, Kim SH. Influence of consecutive night-shift work and working time on insomnia among hospital nurses. Korean J Occup Health Nurs 2020;29(2):133-139 (Korean).

23. Cho YW, Song ML, Morin CM. Validation of a Korean version of the insomnia severity index. J Clin Neurol 2014;10(3):210-215.

24. Bastien $\mathrm{CH}$, Vallières $\mathrm{A}$, Morin $\mathrm{CM}$. Validation of the Insomnia Severity Index as an outcome measure for insomnia research.
Sleep Med 2001;2(4):297-307.

25. Korea Centers for Disease Control and Prevention. 2018 Counseling manual of national health screening program; 2017 [cited 2020 Nov 1]. Available from: https://www.cdc.go.kr/board/ board.es $? \mathrm{mid}=\& \mathrm{bid}=0019 \&$ act $=$ view\&list_no $=138041 \& \mathrm{tag}=$ \&nPage $=20$ (Korean).

26. National Institute on Alcohol Abuse and Alcoholism. Helping patients who drink too much: a clinician's guide; 2005 [cited 2020 Nov 1]. Available from: https://pubs.niaaa.nih.gov/publications/practitioner/cliniciansguide2005/guide.pdf.

27. Lee S, Kim JS, Jung JG, Oh MK, Chung TH, Kim J. Korean alcohol guidelines for moderate drinking based on facial flushing. Korean J Fam Med 2019;40(4):204-211.

28. U.S. Department of Health and Human Services. 2008 Physical activity guidelines for Americans: fact sheet for health professionals on physical activity guidelines for adults [cited 2020 Nov 1]. Available from: https://www.cdc.gov/physicalactivity/ downloads/PA_Fact_Sheet_Adults.pdf.

29. Kim Y, Yang Y, Park H, Kim H. Development of guideline for physical activity and self-help for Koreans. Seoul: Ministry of Health and Welfare; 2012, p. 38-51 (Korean).

30. Portela LF, Kröning Luna C, Rotenberg L, Silva-Costa A, Toivanen $S$, Araújo T, et al. Job strain and self-reported insomnia symptoms among nurses: what about the influence of emotional demands and social support? Biomed Res Int 2015;2015: 820610.

31. Yazdi Z, Sadeghniiat-Haghighi K, Javadi AR, Rikhtegar G. Sleep quality and insomnia in nurses with different circadian chronotypes: morningness and eveningness orientation. Work 2014; 47(4):561-567.

32. Øyane NM, Pallesen S, Moen BE, Akerstedt T, Bjorvatn B. Associations between night work and anxiety, depression, insomnia, sleepiness and fatigue in a sample of Norwegian nurses. PLoS One 2013;8(8):e70228.

33. Thun E, Bjorvatn B, Åkerstedt T, Moen BE, Waage S, Molde H, et al. Trajectories of sleepiness and insomnia symptoms in Norwegian nurses with and without night work and rotational work. Chronobiol Int 2016;33(5):480-489.

34. Härmä $M$, Karhula $K$, Ropponen $A$, Puttonen $S$, Koskinen $A$, Ojajärvi $A$, et al. Association of changes in work shifts and shift intensity with change in fatigue and disturbed sleep: a within-subject study. Scand J Work Environ Health 2018;44(4): 394-402.

35. Knauth P, Rutenfranz J. Experimental shift work studies of permanent night, and rapidly rotating, shift systems. I. Circadian 
rhythm of body temperature and re-entrainment at shift change. Int Arch Occup Environ Health 1976;37(2):125-137.

36. International Labor Organization. R178 - night work recommendation, 1990 (No. 178) [cited 2020 Nov 11]. Available from: https://www.ilo.org/dyn/normlex/en/f?p=NORMLEXP UB:12100:0::NO::P12100_INSTRUMENT_ID:312516.

37. Choi BN . The working conditions of night shift nurses in general wards and issuess related to nursing policy [dissertation].
Seoul: Ewha Womans University; 2018 (Korean).

38. Ropponen A, Koskinen A, Puttonen S, Härmä M. Exposure to working-hour characteristics and short sickness absence in hospital workers: a case-crossover study using objective data. Int J Nurs Stud 2019;91:14-21.

39. Thun E, Le Hellard S, Osland TM, Bjorvatn B, Moen BE, Magerøy $\mathrm{N}$, et al. Circadian clock gene variants and insomnia, sleepiness, and shift work disorder. Sleep Biol Rhythms 2016;14(1):55-62. 